\title{
A EXTENSÃO UNIVERSITÁRIA E SUA CONTRIBUIÇÃO NA FORMAÇÃO DO ESTUDANTE DE GRADUAÇÃO
}

\author{
Maria Santana Ferreira dos Santos ${ }^{1}$ \\ ORCID: 0000-0002-3745-8299 \\ MARIA JosÉ DE PINHO \\ ORCID: 0000-0002-2411-6580
}

\begin{abstract}
Resumo: Este artigo tem como objetivo compreender e evidenciar o papel da universidade do século XXI na perspectiva da Política Nacional de Extensão Universitária, a começar por uma visão complexa da realidade contemporânea. Para tanto, os pressupostos metodológicos estão pautados na revisão bibliográfica e abordagem qualitativa, a partir das principais obras, que podem propiciar o entendimento do contexto contemporâneo, como parte indispensável do pensar, agir, dialogar e fazer da comunidade acadêmica, bem como dados quantitativos e qualitativos da extensão da Universidade Federal do Tocantins. Verificamos que, existem vários programas e projetos entre a universidade e comunidade proporcionada pela extensão universitária, entendida como um processo interdisciplinar educativo, cultural, científico e político.
\end{abstract}

Palavras-chave: Política de Extensão. Responsabilidade Social. Universidade. Graduação.

1 Doutorado em Educação pela Universidade de Brasília. Graduação em Pedagogia UFT. Mestrado em Educação. Professor Adjunto II da Universidade Federal do Tocantins. Pró Reitora de Extensão da Universidade Federal do tocantins.msfsantos@uft.edu.br .

2 Doutorado em Educação e Currículo pela Pontifícia Universidade Católica de São Paulo e Pós-Doutorado em Educação pela Universidade do Algarve (Portugal). Professora da Universidade Federal do Tocantins - UFT e do Programa de Pós-Graduação em Letras Mestrado em Ensino de Língua e Literatura e Programa de Pós-Graduação em Educação. Bolsista Produtividade. Mestrado em Educação pela Universidade Federal de Pernambuco; Graduação em História e graduação em Pedagogia. E-mail: (mjpgon@mail.uft.edu.br). 


\title{
UNIVERSITY EXTENSION AND ITS CONTRIBUTION IN GRADUATE STUDENT TRAINING
}

\begin{abstract}
This article aims to understand and highlight the role of the 21st century university in the perspective of the National University Extension Policy, starting with a complex view of contemporary reality. To this end, the methodological assumptions are based on the literature review and qualitative approach, from the main works, which can provide the understanding of the contemporary context, as an indispensable part of thinking, acting, dialoguing and making the academic community, as well as quantitative and qualitative studies of the extension of the Federal University of Tocantins. We found that there are several programs and projects between the university and the community provided by the university extension, understood as an interdisciplinary educational, cultural, scientific and political process.

Keywords: Extension Policy. Social responsibility. University. University graduate.
\end{abstract}

\section{EXTENSIÓN UNIVERSITARIA Y SU CONTRIBUCIÓN EN LA FORMACIÓN DE ESTUDIANTES GRADUADOS}

Resumen: Este artículo tiene como objetivo comprender y resaltar el papel de la universidad del siglo XXI en la perspectiva de la Política Nacional de Extensión Universitaria, comenzando con una visión compleja de la realidad contemporánea. Por lo tanto, los supuestos metodológicos se basan en la revisión de la literatura y el enfoque cualitativo, de los trabajos principales, que pueden proporcionar la comprensión del contexto contemporáneo, como una parte indispensable del pensamiento, la actuación, el diálogo y la formación de la comunidad académica, así como cuantitativa y de la extensión de la Universidad Federal de Tocantins. Descubrimos que existen varios programas y proyectos entre la universidad y la comunidad proporcionados por la extensión universitaria, entendidos como un proceso educativo, cultural, científico y político interdisciplinario.

Palabras claves: Política de extensión. Responsabilidad social. Universidad. Graduación.

\section{INTRODUÇÃO}

A sociedade contemporânea é fruto de constantes mudanças. Desde as suas raízes, novas ideias, crises e transformações vêm sendo interligadas. Tais trajetórias, principalmente a partir da modernidade, marcaram o todo da vida humana

Diante de frequentes modificações, a universidade acompanhou as transições com novas perspectivas epistemológicas e finalidades formativas na educação superior. Com a chegada do século XXI e diante de cenários diversos e velozmente mutáveis, faz-se necessário compreender a Política Nacional de Extensão Universitária, partindo do princípio da Responsabilidade Social. 
No papel de vanguarda, a universidade é lócus ideal para delineamento de novos estudos, leituras e atitudes epistemológicas que possibilitam reconfigurar conhecimento para além das exigências mercadológicas, do paradigma da ciência moderna que empregou as ciências, inclusive a de humanas, dos seus procedimentos e lógica cognitivo-instrumental. Tais fatores impedem e limitam a busca por um conhecimento inovador e criativo que revalorize os saberes por meio do agir da sociedade, cujas práticas são partilhar valores, cultura e conhecimentos, no sentido da integração entre conhecimento científico, o pensamento do senso comum e os saberes populares em prol dos problemas sociais da humanidade.

Nessa mudança do século XX para o XXI, de moderno para o contemporâneo, a universidade perpassou e continua a vivenciar momentos de crise em que suas conviç̧ões, fragmentações, repetições e certezas não a sustentam mais no caminho de novas produções. Contudo, o que lhe ampara, nesta ocasião, é o oceano de incertezas, como orientação para a construção de novos conhecimentos (MORIN, 2001).

Diante desse cenário de transições, este texto tem como objetivos compreender e evidenciar o papel da universidade do século XXI na perspectiva da Política Nacional de Extensão Universitária, a começar por uma visão complexa da realidade contemporânea. Para tanto, os pressupostos metodológicos estão pautados na revisão bibliográfica com abordagem qualitativa, a partir das principais obras, que podem propiciar o entendimento do contexto contemporâneo, como parte indispensável do pensar, agir, dialogar e fazer da comunidade acadêmica, bem como dados quantitativos e qualitativos da extensão da Universidade Federal do Tocantins - UFT.

A proposta de discussão advém da visão de que o direito à educação sempre esteve presente nas constituições brasileiras. Porém, somente no final dos anos de 1970 e início dos anos de 1980 e diante da crise mundial do sistema capitalista e da reforma do Estado brasileiro, o ensino superior começou a ser repensado como política pública.

Baseado no aparato legal da Política Nacional de Extensão Universitária e na Resolução do Conselho Nacional da Educação/Câmara de Educação Superior (CNE/CES) no 7, de 18 de dezembro de 2018, que estabelece as Diretrizes para a Extensão na Educação Superior Brasileira e regimenta o disposto na Meta 12.7 da Lei no 13.005/2014, responsável por aprovar o Plano Nacional de Educação (PNE) 2014-2024, é possível compreender e evidenciar a responsabilidade social da universidade e a sua contribuição em relação à inclusão social, ao desenvolvimento econômico e social.

Consoante a isso, os documentos institucionais deverão pautar suas ações e diretrizes, fundamentando-se em uma política de extensão que dialogue com o 
ensino e a pesquisa, além de ter como foco as diretrizes contidas na Política Nacional de Extensão Universitária, tais como:

- Interação da Universidade com a Comunidade;

- Interprofissionalidade e interdisciplinaridade;

- Indissociabilidade entre Ensino, Pesquisa e Extensão;

- Impacto na formação docente;

- Impacto e transformação Social.

O desafio do cumprimento das diretrizes da política de extensão universitária é necessário para reforçar o diálogo entre universidade e sociedade, que também é um espaço de formação no ensino de graduação.

\section{FUNDAMENTOS LEGAIS E TEÓRICOS DA RESPONSABILIDADE SOCIAL NAS UNIVERSIDADES}

A educação é assegurada pela Constituição Federal de 1988, em seu artigo 206, como "direito de todos e dever do Estado e da família, será promovida e incentivada com a colaboração da sociedade, visando ao pleno desenvolvimento da pessoa, seu preparo para o exercício da cidadania e sua qualificação para o trabalho". Para garantir esse direito, o ensino será ministrado observando os seguintes princípios: igualdade de condições para acesso e permanência na escola.

- Liberdade de aprender, ensinar, pesquisar e divulgar o pensamento, a arte e o saber;

- Pluralismo de ideias e de concepções pedagógicas, e coexistência de instituições públicas e privadas de ensino;

- Gratuidade do ensino público em estabelecimentos oficiais;

- Valorização dos profissionais do ensino, garantidos na forma da lei, planos de carreira para o magistério público, piso salarial profissional e ingresso exclusivamente por concurso público de prova e títulos;

- Gestão democrática do ensino público, na forma da lei;

- Garantia de padrão de qualidade. (BRASIL, 2006).

A Constituição Federal estabelece o princípio da autonomia universitária em seu artigo 207: "As universidades gozam de autonomia didático-científica, administrativa e de gestão financeira patrimonial, e obedecerão ao princípio de indissociabilidade entre ensino, pesquisa e extensão", evidenciando a questão central relacionada ao conceito de responsabilidade social, aplicado às instituições educacionais. 
Nesse sentido, a presente discussão teórica baseia-se em autores como Boaventura de Souza Santos (2011), permitindo refletir sobre o reforço da responsabilidade social da universidade. Boaventura Santos (2011, p. 65) reforça o princípio da indissociabilidade entre ensino, pesquisa e extensão, ao afirmar que "as reformas devem partir do pressuposto que no século XXI só há universidade quando há formação graduada e pós-graduada, pesquisa e extensão. Sem qualquer destes, há ensino superior, não há universidade".

Portanto, a promoção do conhecimento científico e a formação profissional de nível superior cabem às universidades, conforme determina o artigo 52, da LDB (BRASIL, 1996): “As universidades são instituições pluridisciplinares de formação dos quadros profissionais de nível superior, de pesquisa, de extensão e de domínio e cultivo do saber humano", caracterizadas por "produção intelectual institucionalizada mediante o estudo sistemático dos temas e problemas mais relevantes, tanto do ponto de vista científico e cultural, quanto regional e nacional; [...]", tendo como desafio promover as transformações e as mudanças sociais.

Ao pensar sobre as transformações e as mudanças na relação entre a universidade e a sociedade, no artigo "Por uma Universidade socialmente relevante", Alex Fiúza Naomar de Almeida e Renato Janine (2009) apontam o triplo desafio para a Universidade Pública brasileira: o padrão de qualidade; a universalidade de acesso a todos e a todas que demonstrarem vocação, aptidão e motivação; e o desenvolvimento de programas sociais relevantes capazes de contribuir para a solução de problemas.

Vale ressaltar que, dentre os objetivos da universidade, já se acham presentes esses desafios que alinham a universidade pública, segundo os autores, em um contexto globalizado, econômico, social e democrático, lançando-a como "paradigma ético para o mundo". Segundo os autores, "se uma universidade europeia ou norte-americana pode dar-se ao luxo de exibir, como principal distintivo, a pertinência científica (...), a universidade brasileira precisa demonstrar, além da qualidade acadêmico-científica e sem renunciar a ela, relevância social” (2009, p. 294).

Ao se discutir a responsabilidade social universitária, pressupõe-se que as universidades tenham autonomia didático-científica, administrativa, financeira e patrimonial conquistada historicamente. Contudo, por ela estar vinculada aos órgãos governamentais, essa autonomia, de certa forma, torna-se parcial face às regulamentações nem sempre adequadas ao cumprimento de sua missão. Assim, seria contraditório falar de responsabilidade social da universidade sem autonomia. Tal contradição se apresenta em meio às três crises anunciadas por Santos (2011), nos últimos vinte anos: a de hegemonia, a de legitimidade e a institucional. 
Segundo o autor, a crise de hegemonia resulta de funções sociais contraditórias da universidade, visto que, além de produtora da alta cultura e formadora das elites, desde os tempos da Idade Média, a universidade é também produtora de padrões culturais médios e de conhecimentos instrumentais, na intenção de formar mão de obra qualificada. A incapacidade de desempenhar plenamente essas duas funções teria levado os agentes econômicos a privilegiarem meios alternativos fora da universidade. A crise de legitimidade foi provocada pela perda da consensualidade dada à universidade como produtora do conhecimento, em face da contradição entre a hierarquização dos saberes especializados.

Neste processo, verificam-se alguns princípios orientadores das políticas educacionais para o ensino superior, propostos por Santos (2011, p. 61): enfrentar o novo com o novo; lutar pela definição da crise para sair de sua posição defensiva e lutar pela definição de universidade. Além disso, o autor apresenta cinco fatores para reconquistar a legitimidade da universidade em cinco áreas de ação:

- $\mathrm{O}$ acesso sem discriminação e garantia da permanência;

- A extensão como prestação de serviço à sociedade atendendo diferentes segmentos, que não sejam pautados por sua rentabilidade, mas num apoio solidário à solução dos problemas, da exclusão e da discriminação sociais;

- A pesquisa-ação como articulação dos interesses sociais e dos interesses de pesquisa para além das demandas de mercado, numa atuação integrada de ensino, pesquisa, para definição e elaboração dos projetos de pesquisa, envolvendo a participação da comunidade e seu beneficiamento com os resultados da pesquisa;

- A ecologia dos saberes é "uma forma de extensão ao contrário", de fora para dentro da universidade, trata do diálogo entre saber popular e conhecimento científico, de perceber a validade de outros conhecimentos, de reverter uma "injustiça cognitiva";

- Relação entre a produção e a difusão do saber pedagógico, da pesquisa educacional e da formação de docentes para a escola pública, espaço que é ocupado pela progressiva privatização da formação docente.

Reconhece-se que, a partir disso, a proposta do autor é um programa de responsabilização social da universidade, pois, somente por meio dele, será possível lutar pela sua legitimidade. No entanto, para que isso ocorra, a universidade terá que ser dotada das condições adequadas tanto financeiras quanto institucionais.

A responsabilidade social de uma instituição educativa, segundo Dias Sobrinho (2008, p. 195), diz respeito "ao cumprimento, com qualidade e sentido social e público, de suas finalidades e seus objetivos essenciais: a formação [...], valores, [...] a solidariedade, a liberdade, a justiça, os direitos públicos, o respeito à diversidade [...]". Nesse cenário, a responsabilidade social da universidade tem como capacidade 
definir seu próprio destino em meio às incertezas e aos desafios. Assim, a política de extensão universitária torna-se uma atividade de fundamental importância.

Com o fortalecimento da sociedade civil, principalmente nos setores comprometidos com as classes populares e em oposição ao enfraquecimento da sociedade política, ocorrido na década de 1980, em especial nos seus últimos anos, foi possível pensar a elaboração de uma nova concepção de universidade, baseada na redefinição das práticas de ensino, pesquisa e extensão até então vigentes.

O tratamento assistencialista dado à extensão deve ser eliminado por ter uma posição estratégica nas atividades de ensino, pesquisa e extensão, desenvolvidas pela universidade. Segundo Vallaeys (2006, p. 38), "a universidade precisa tratar de superar o enfoque da "projeção social e extensão universitária" como "apêndices" bem intencionados de sua função central de formação estudantil e produção de conhecimentos, a fim de poder atender ao que de fato está a exigir a Responsabilidade Social Universitária”.

\section{A RESPONSABILIDADE SOCIAL E A EXTENSÃO UNIVERSITÁRIA}

As grandes transformações e as mudanças sociais trazidas pela globalização e pelos avanços das tecnologias de informação e comunicação exigem das instituições de educação superior a formação do cidadão com responsabilidade e ética. Assim, o ensino, a pesquisa e a extensão são atividades acadêmicas voltadas para a sociedade e o desenvolvimento do cidadão, pois como afirma Santos (2011, p. 113), "A universidade é um bem público intimamente ligado ao projeto de país".

Nas universidades, a responsabilidade social está atrelada normalmente à extensão universitária, considerada a sua relação com a sociedade juntamente com os demais segmentos o ensino e pesquisa. Entretanto, a concepção de responsabilidade social não deve estar voltada somente às ações específicas de extensão, tendo em vista que o processo educacional é sistêmico e indissociável. A extensão é definida no instrumento de avaliação como "Processo interdisciplinar educativo, cultural, científico e político, sob o princípio constitucional da indissociabilidade entre ensino e pesquisa, que promove a interação transformadora entre a IES e outros setores da sociedade" (BRASIL, 2014, p. 33).

Nessa perspectiva, Santos (2011, p. 73) afirma que "a reforma da universidade deve conferir uma nova centralidade às atividades de extensão", atribuindo-lhe "uma participação ativa na construção da coesão social, no aprofundamento da democracia, na luta contra a exclusão social e a degradação ambiental, na defesa da diversidade cultural". 
A extensão universitária contempla os seguintes indicadores: a coerência entre o Plano de Desenvolvimento Institucional-PDI as práticas de extensão; as ações acadêmico-administrativas de extensão, levando em conta o apoio à realização de programas, projetos, atividades e ações; os canais de comunicação externa e interna, considerando o acesso da comunidade externa e interna às informações acerca dos resultados das avaliações recentes, da divulgação dos cursos, da extensão e pesquisa, da existência de mecanismos de transparência institucional, da ouvidoria, entre outros; as fontes de recursos previstas/executadas para o custeio e aos investimentos em ensino, extensão, pesquisa e gestão; o planejamento financeiro (orçamento com as respectivas dotações e rubricas) previsto/executado relacionado com a gestão do ensino, da pesquisa e da extensão (BRASIL, 2014).

A universidade como um bem público, deve destacar-se pela sua responsabilidade social. Dessa maneira, por considerar a Política Nacional de extensão, é de suma importância a sua contribuição nos aspectos sociais, culturais, ambientais e econômicos da sociedade. Assim, registram-se na tabela 1 algumas ações realizadas pela UFT.

TABELA 1: INDICADORES DE AÇÕES - 2017

\begin{tabular}{|c|c|}
\hline \multicolumn{2}{|c|}{ INDICADORES DAS AÇÕES DE EXTENSÃO - 2017} \\
\hline \multicolumn{2}{|c|}{ AÇÕES DE EXTENSÃO CADASTRADAS } \\
\hline Programa & 36 \\
\hline Projeto & 240 \\
\hline Curso & 97 \\
\hline Evento & 260 \\
\hline Total & 633 \\
\hline
\end{tabular}

Fonte: PRÓ-REITORIA DE EXTENSÃo DA UFT.

Desse quantitativo de ações, estão divididas nas seguintes áreas temáticas conforme explicita a figura 1: 
ÁREA TEMÁTICA DAS AÇÕES DE EXTENSÃO EM 2017

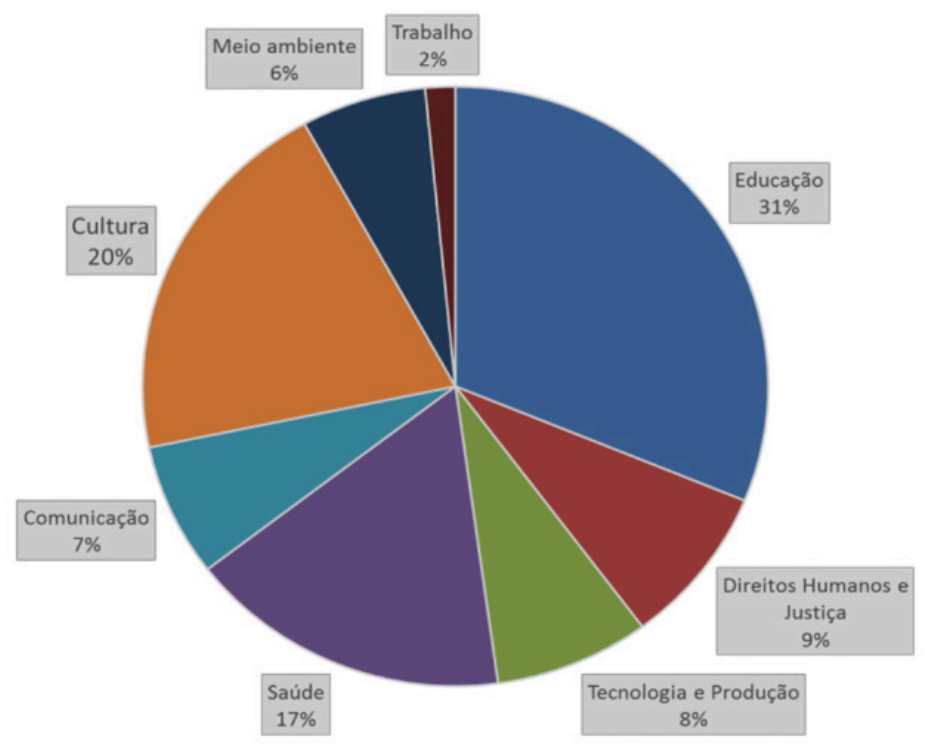

FICURA 1: GRÁFICO dA ÁREA TEMÁTICA DAS AÇões - 2017

FontE: PRÓ-REITORIA DE EXTENSÃO DA UFT.

No ano de 2018, os dados mostram que houve um aumento significativo no número de ações de extensão, como exposto a seguir na tabela 2 .

Fonte: PRÓ-REITORIA DE EXTENSÃO DA UFT.

\begin{tabular}{|c|c|}
\hline \multicolumn{2}{|c|}{ INDICADORES DAS AÇÕES DE EXTENSÃO - 2018} \\
\hline \multicolumn{2}{|c|}{ AÇÕES DE EXTENSÃO CADASTRADAS } \\
\hline Programa & 30 \\
\hline Projeto & 255 \\
\hline Curso & 115 \\
\hline Evento & 348 \\
\hline Total & 748 \\
\hline
\end{tabular}

Fonte: PRÓ-REITORIA DE EXTENSÃo dA UFT. 
Esse quantitativo de ações está dividido nas seguintes áreas temáticas conforme explicita a figura 2:

ÁREA TEMÁTICA DAS AÇÕES DE EXTENSÃO EM 2018

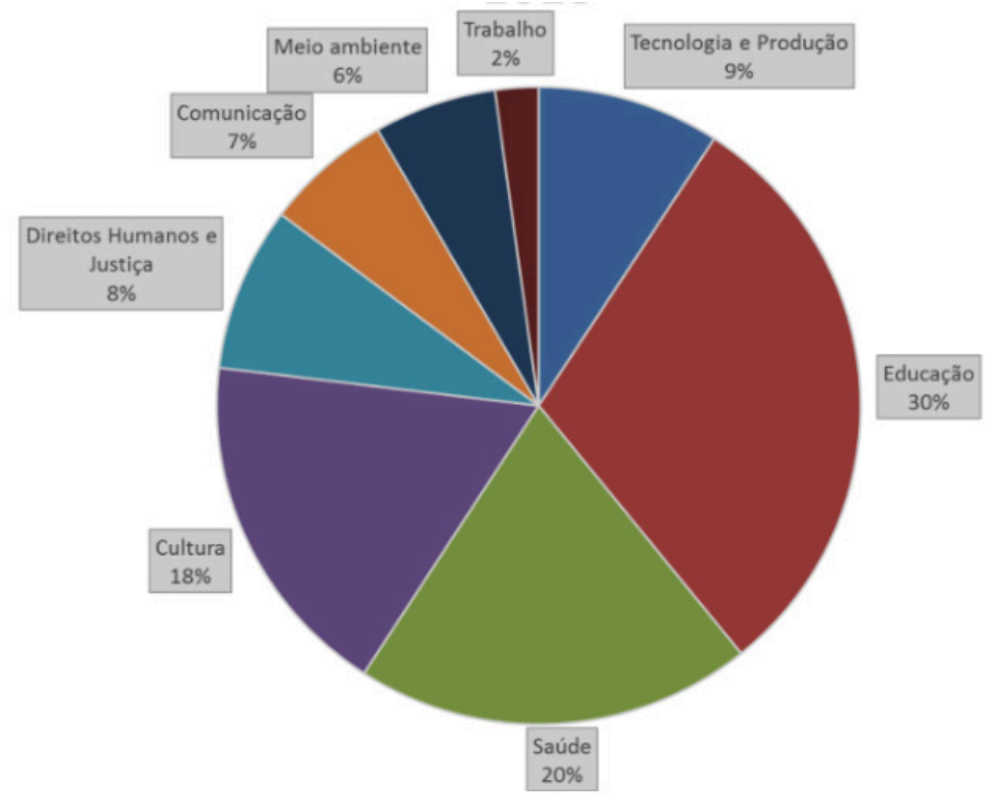

FIGURA 2: GRÁFICO DA ÁREA TEMÁTICA DAS AÇÕ̃S-2018

FontE: PRÓ-REITORIA DE EXTENSÃO DA UFT.

Ao analisar comparativamente os dados, observa-se que houve um aumento nos números de projetos, eventos e cursos e um crescimento no número de ações na área da saúde. Constata-se, por meio desses dados, que a extensão na Universidade Federal do Tocantins - UFT vem combatendo os problemas principalmente nas áreas de Educação, Saúde e Cultura.

\section{PROGRAMAS E PROJETOS DE EXTENSÃO DA UNIVERSIDADE FEDERAL DO TOCANTINS}

A Universidade Federal do Tocantins - UFT foi pensada, planejada e consolidada em uma região privilegiada dentro do contexto brasileiro, que é a Região Norte. Uma região de grande diversidade cultural, de múltiplos e ricos saberes, e de povos diversos. No entanto, é também uma região onde possui baixos índices de desenvolvimento humano e social. Mediante isso, o seu projeto não pode ser pensado de forma isolada, um projeto, no qual, essa população não tem lugar de protagonismo. 
Outro fator de destaque para uma universidade inserida em uma Região carregada de sentidos e de significados é a necessidade de trabalhar de maneira interdisciplinar e intercultural, sob a égide de um pensamento descolonizador. Nesse estudo, adotou-se o conceito de interculturalidade de Marín (2009), onde é:

\footnotetext{
O reconhecimento mútuo de todas as culturas, sem hierarquização. Essa é a primeira condição para elaborar a análise da descolonização do saber e do poder que lhe é inerente. $\mathrm{O}$ processo histórico da colonização europeia foi constituído em um contexto de dominação cultural, social, econômica e política. À medida que a cultura eurocêntrica não respeita a biodiversidade, nem a diversidade cultural, as referências reais e as significações simbólicas dos contextos locais são pervertidas. (MARÍN, 2009, p. 127).
}

Quando o autor enfatiza o "reconhecimento mútuo", ele está dizendo que os saberes têm o mesmo valor, porém, perspectivas diferentes e complementares. Para Cunha (2009),

Nada ou quase nada ocorre no conhecimento tradicional da mesma forma como ocorre no conhecimento científico. Não há dúvida, no entanto, de que o conhecimento científico é hegemônico. Essa hegemonia manifesta-se até na linguagem comum em que o termo "ciência" é não-marcado, como dizem os linguistas. Isto é: quando se diz simplesmente "ciência", "ciência" tout court, está se falando de ciência ocidental; para falar de ciência tradicional, é necessário acrescentar o adjetivo. (CUNHA, 2009, p. 79)

Na Universidade Federal do Tocantins, essa valorização dos saberes vem também através do ingresso de estudantes indígenas e quilombolas em todos os cursos de graduação e pós-graduação. Desde o ano de 2004, através da Política de Ações Afirmativas, registrou-se o ingresso nos cursos de graduação de $5 \%$ de estudantes indígenas, e em 2014, o ingresso de 5\% de estudantes quilombolas. Com estes dados, somando-se o que estabelece a Lei n ${ }^{\circ} .12 .711$ de 2012, atualmente a UFT reserva $60 \%$ de suas vagas para as cotas raciais e sociais. No caso da Pós-Graduação, a partir de 2017, estão sendo reservadas até 50\% das vagas para pretos, pardos, indígenas, quilombolas e com deficiência.

No entanto, a grande dificuldade é a permanência com sucesso dos estudantes indígenas. Diante disso, foi criada em 2018 a coordenação de ações afirmativa ligada a Pró - reitoria de Extensão com o objetivo de ser o ponto de referência da universidade para as questões afirmativas - indígena, negra, deficiência, LGBTQI. A principal atividade realizada pela Proex, para as ações afirmativas foi à construção da politica através do debate em cada campus e com a participação de estudantes, servidores e membros da comunidade externa. 
Nesse sentido, um dos objetivos da universidade é a produção do conhecimento no que concerne a sua contribuição para o desenvolvimento cultural, por meio de ações que promovam os direitos humanos, a educação, a cultura, a saúde, o trabalho, as tecnologias, o meio ambiente, a comunicação; com atenção especial para as populações em condições de vulnerabilidade, considerando a diversidade de gênero, raça, credo, idade e etnia. Nesse contexto, as atividades de extensão voltadas para a promoção da arte e da cultura destinadas às demandas do entorno social e cultural - articulando os conhecimentos e os currículos - deverão estar apoiadas e difundidas nas diversas manifestações culturais advindas das demandas da comunidade acadêmica.

Tais ações poderão ser fortalecidas na relação, por exemplo com cursos na área de Artes, Teatro, Educação do Campo, Música, entre outros. Nesse ponto, valoriza-se tanto o saber das atividades acadêmicas de ensino, pesquisa e extensão quanto os saberes populares. Assim, ações pontuais podem ser fomentadas, por meio de práticas dentro do ambiente acadêmico, resultando em produtos culturais, por exemplo, em uma peça teatral ou um show musical.

Além disso, existem os programas e os projetos universitários que visam à sensibilização e à tomada de consciência da comunidade sobre o valor dos ecossistemas, a realidade ambiental e a participação no processo de preservação dos recursos naturais, no sentido de promover reflexões que sirvam de estímulo e interesse pela questão ambiental.

No mesmo sentido, as ações de extensão voltadas para a inclusão social perpassam por diversas áreas temáticas, como nas áreas de educação, comunicação e cultura.

Dentre as ações desenvolvidas, convém destacar o Programa Centro de Referência em Cidadania e Direitos Humanos, aprovado pelo Edital Nacional do Ministério da Educação. A proposta previa ações mediadoras com instituições parceiras que garantam o atendimento jurídico e psicológico, sendo o atendimento social e antropológico efetuado pelos docentes participantes do Programa, com o intuito de instrumentalizar os indivíduos atendidos para que reivindiquem seus direitos e que possam conquistar a autonomia. O programa tem como meta superar a mera prestação de serviços à comunidade, proporcionando o desenvolvimento de um Programa que se relacione com a investigação científica e a produção de conhecimentos voltados para a qualificação do ensino a partir da realidade sociocultural, missão e valores da instituição de ensino superior.

No mesmo intuito, há programas nas universidades que se propõem a capacitar professores e gestores para o uso pedagógico das tecnologias digitais de informação e comunicação (TDIC), com a finalidade de possibilitar a inclusão digital escolar e a apropriação tecnológica e pedagógica dessas tecnologias. 
Além disso, algumas ações foram contempladas nos editais do Programa de Extensão Universitária (Proext/MEC) e do Programa Institucional de Bolsa de Extensão (Pibex), com relação à temática da inclusão social. São elas: Projeto: Bom de bola, bom na escola; Direitos de fato: o SUAS em ação; Esporte: educando para a vida; Bom Saque; Projeto: Cooperar mais competir menos; Qualidade de vida para os mais velhos: uma tecnologia social multidisciplinar; Formação do Pacto Nacional pela alfabetização na idade certa; Formação continuada de professores Alfabetizadores do Estado do Tocantins; Universalização da oferta de língua estrangeira. Grande parte desses projetos continua suas ações mesmo após o prazo de vigência do edital, como no caso do projeto de qualidade de vida para os mais velhos.

A Universidade Federal do Tocantins, por meio da Resolução do Conselho de Ensino, Pesquisa e Extensão (Consepe) no 09/2015, normatizou os Programas Institucionais: Programa de Acesso Democrático à Universidade (PADU) e o Programa de Acesso Democrático de Indígenas e Quilombolas (Padiq). O PADU faz parte da política de extensão da UFT e tem por finalidade estabelecer a igualdade de acesso e oportunidade de egressos de escolas públicas e populações com vulnerabilidade socioeconômica, minimizando as consequências históricas de exclusão social-educacional desses segmentos da sociedade, atuando desta forma como política institucional de responsabilidade social da UFT. Esse programa está sendo trabalhado atualmente em cinco municípios tocantinenses e atende 300 pessoas externas e 25 bolsistas de graduação. Em 2018, foram obtidos bons resultados de inclusão dessa população no ensino superior. Os relatos mostram que o programa tem contribuído significativamente para a vida da comunidade atendida.

A responsabilidade social universitária, considerando a sua contribuição para o desenvolvimento econômico em articulação com os setores produtivos da sociedade, pode contribuir para o fortalecimento da extensão universitária. Nesse sentido, muitas universidades implantaram programas que se referem ao comprometimento da universidade com a reparação das distorções históricas que afastam a maior parte da população brasileira da graduação em instituições públicas de ensino. Em tais programas, os candidatos com perfis de vulnerabilidade socioeconômica são preparados para que posteriormente possam ingressar na universidade. Por meio de relações com os setores produtivos, a Universidade toma conhecimento dos problemas, dos desafios e dos interesses econômicos, direcionando seus esforços na intenção de contribuir com soluções para o desenvolvimento econômico regional e nacional. Entre os setores produtivos, destacam-se aqueles comprometidos com a economia solidária e as tecnologias sociais.

A Política Nacional de Extensão Universitária (2012, p. 20) reafirma a Extensão Universitária como: 
o mecanismo por meio do qual se estabelece a inter-relação da Universidade com os outros setores da sociedade, com vistas a uma atuação transformadora, voltada para os interesses e necessidades da maioria da população e propiciadora do desenvolvimento social e regional, assim como para o aprimoramento das políticas públicas.

Dessa forma, as políticas de extensão e cultura devem enfatizar o papel da extensão articulada com o ensino e a pesquisa de forma indissociável. Do mesmo modo, devem viabilizar a relação transformadora entre a universidade e a sociedade, estabelecendo o vínculo entre o conhecimento acadêmico, a intervenção social e o comprometimento com o desenvolvimento sociocultural da comunidade.

\section{REFLEXÕES FINAIS}

A responsabilidade social universitária é uma dimensão que relaciona vários aspectos quanto aos conhecimentos produzidos e difundidos na universidade, variáveis conforme o seu contexto social. Dessa maneira, são promovidas ações com base em princípios éticos que asseguram o desenvolvimento, considerando a sua contribuição nos âmbitos social, cultural, ambiental e econômico. Logo, essa responsabilidade universitária é discutida como um compromisso social e educacional da universidade com a igualdade social, o meio ambiente, os direitos humanos, a ciência, a tecnologia, entre outros.

Diante disso, a relação mais direta entre universidade e comunidade é proporcionada pela extensão universitária, entendida como um processo interdisciplinar educativo, cultural, científico e político, que, sob o princípio da indissociabilidade, promove a interação transformadora entre universidade e outros setores da sociedade.

Entende-se, portanto, que a universidade do século XXI precisa ser aberta e romper com o modelo tradicional de instituição, como um sistema fechado, e lutar pela sua autonomia e legitimidade, no sentido de construir a sua identidade institucional e cumprir a sua responsabilidade social.

A política de extensão da Universidade Federal do Tocantins avalia a responsabilidade tendo como foco a inclusão social, o desenvolvimento econômico e social, a defesa do meio ambiente, a memória cultural, a produção artística e o patrimônio cultural. Isso leva a UFT a promover ações relacionadas a ensino, pesquisa, extensão e gestão, em uma análise sistêmica e global. A responsabilidade social da referida universidade representa um reforço para a sociedade por ser lugar de elevada produção e formação de seus cidadãos para a vida e para o mercado de trabalho, ao influenciar suas condições de vida, oferecer um retorno à sociedade e produzir conhecimentos diversos, próprio de um lócus reflexivo, crítico 
e inventivo. Dessa forma, está garantida uma docência da educação superior com capacidade para formar sujeitos socialmente e politicamente comprometidos e motivados pelo conhecimento.

\section{REFERÊNCIAS BIBLIOGRÁFICAS}

BRASIL. Lei de Diretrizes e Bases da Educação Nacional. Lei no 9.394, de 20 de dezembro de 1996. Estabelece diretriz e bases da educação nacional. Disponível em: http://www.planalto.gov.br/ccivil_03/Leis/L9394.htm. Acesso em: 30 de set. de 2019.

BRASIL. Constituição da República Federativa do Brasil. Disponível em. http://www.planalto.gov.br/ccivil_03/constituicao/constituicaocompilado. htm. Acesso em 28 maio de 2015.

CUNHA, M. C. da. Cultura com aspas e outros ensaios. São Paulo: Cosac Naify, 2009.

FORPROEX. Fórum de Pró-Reitores de Extensão das Universidades Públicas Brasileiras. Política Nacional de Extensão Universitária. Manaus, 2012.

MARÍN, J. Interculturalidade e descolonização do saber: relações entre saber local e saber universal, no contexto da globalização. Visão Global, Joaçaba, v. 12, n. 2, p. 127-154, 2009. Disponível em: https://portalperiodicos.unoesc. edu.br/index. Acesso em: abr. de 2018.

MELlO, A. F. de; ALMEIDA FILHO, N.; RIBEIRO. R. J. Por uma Universidade Socialmente Relevante. Atos de Pesquisa em Educação - Programa de Pós-Graduação em Educação/FURB, v. 4, no 3, p. 292-302, set./dez. 2009.

SANTOS, B. de S. A universidade no século XXI: para uma reforma democrática e emancipatória da Universidade. 3. ed. São Paulo: Cortez, 2011.

VALLAEYS, F. O Que Significa Responsabilidade Social Universitária? In: Revista Estudos, n. 36, p.37. Brasília, ABMES, 2006. 